\title{
Determination of Groundwater Surface using Damped Least-Squares Inversion in the Bekasap Field, Riau
}

\author{
Penentuan Muka Air Tanah Dengan Pemodelan Inversi Damped Least-Squares Pada Lapangan \\ Bekasap Riau
}

\author{
Pinehas, D.* dan Warsa \\ Teknik Geofisika, Fakultas Teknik Pertambangan dan Perminyakan, Institut Teknologi Bandung, \\ Jalan Ganesa No 10, Bandung, 40132 \\ *Email: davidpinehas7@gmail.com
}

Submit: 15 Mei 2019; Revised: 10 Juni 2019; Accepted: 10 Agustus 2019

\begin{abstract}
Groundwater is a primary water source for the sustainability of human life. Groundwater is located in the subsurface area in the saturated zone called aquifer. The presence of an aquifer can be identified through a geophysical survey by determining the upper boundary of the aquifer called the groundwater table. DC Resistivity geoelectrical method is one of the geophysical measurements which is effective to be used to determine the depth of the water table. Measurements were performed using the Wenner electrode configuration in Bekasap to attain preferable depth resolution. The process of measurement data modelling yields rms error. In order to reduce the rms error, damped least-squares is applied into the inversion solution. This process will improve the model parameter iteratively until the minimum rms error is obtained. The damped least-squares modeling was tested on three synthetic models which have Resistivity variation. Furthermore, the damped least-squares was applied on the observed data at Bekasap. From the processing and modeling using damped least-squares, the depth of the groundwater table and aquifer can be obtained.
\end{abstract}

Keywords:

Abstrak: Air tanah merupakan sumber air utama yang dapat dimanfaatkan untuk kelangsungan hidup manusia. Air tanah terletak di bawah permukaan bumi pada zona tersaturasi yang disebut sebagai aquifer. Keberadaan akuifer dapat diidentifikasi melalui survei geofisika dengan menentukan batas atas akuifer yang disebut muka air tanah. Metode geolistrik DC Resistivity merupakan salah satu metoda geofisika yang dapat digunakan untuk menentukan kedalaman muka air tanah. Pada pengukuran data lapangan di Bekasap digunakan konfigurasi pengukuran Wenner untuk mendapatkan resolusi vertikal yang lebih baik. Pemodelan data hasil pengukuran akan menghasilkan rms error. Salah satu metode untuk mengurangi atau memperkecil rms error tersebut adalah dengan menerapkan damped least-squares pada proses pemodelan inversi. Proses ini akan memperbaharui parameter model secara iterasi hingga didapatkan rms error minimum. Pemodelan damped LeastSquares diaplikasikan pada tiga buah model sintetik yang memiliki variasi tahanan jenis. Kemudian Damped Least-
Squares diaplikasikan untuk memodelkan data hasil pengukuran di Bekasap. Dari hasil pengolahan dan pemodelan damped Least-Squares, kedalaman muka air tanah dan kedalaman aquifer dapat ditentukan.

Kata kunci:

\section{PENDAHULUAN}

Air merupakan salah satu hal penting bagi kelangsungan hidup manusia. Sumber air utama yang dapat dimanfaatkan untuk kebutuhan pokok manusia merupakan air tanah. Air tanah digunakan untuk irigasi, industri, dan pemuki- man. Air tanah adalah air yang terdapat di bawah permukaan tanah pada lapisan yang disebut aquifer. Untuk mengetahui keberedaan aquifer ini, perlu dilakukan survey geofisika terlebih dahulu. Survey dilakukan pada permukaan bumi untuk mengetahui ketebalan serta kedalaman lapisan aquifer Dobrin dan Savit (1988); Kirsch (2009).

Kondisi bawah permukaan bumi terdiri dari lapisanlapisan yang tersusun dari material tertentu. Materialmaterial tersebut memiliki sifat kelistrikan yang berbeda. Sifat kelistrikan ini salah satunya dipengaruhi oleh kandungan air pada suatu lapisan. Jika suatu lapisan mengandung air tanah, lapisan tersebut tersebut memiliki nilai resistivitas yang rendah dibanding lapisan sekitarnya Koefoed (1979). Metode geofisika yang tepat untuk melakukan survey air tanah adalah metode geolistrik. Terdapat beberapa jenis pengukuran dari metode geolistrik, yaitu: SP (Self Potential), Resistivitas, dan GPR (Ground Penetrating Radar). Pengukuran Resistivitas sendiri terdiri dari metode AC Resistivity dan DC Resistivity Ghosh (1970, 1971).

Pemodelan data hasil pengukuran akan menghasilkan rms error. Salah satu metode untuk mengurangi atau memperkecil rms error tersebut adalah dengan menerapkan damped least-squares pada proses pemodelan inversi Ekinci dan Demirci (2008). Proses ini akan memperbaharui parameter model secara iterasi hingga didapatkan rms error minimum.

Penelititian ini bertujuan untuk memodelkan tahanan 


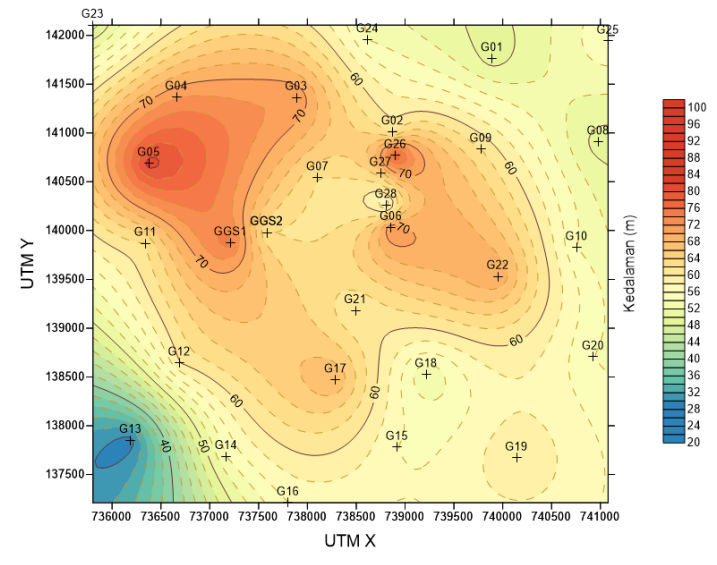

Gambar 1. Peta topografi titik pengukuran Vertical Electrical Sounding.

jenis bawah permukaan pada daerah pengukuran Vertical Electrical Sounding di Bekasap dengan pemodelan inversi damped least-squares. Selain itu juga untuk menentukan muka air tanah dan peta penyebaran muka air tanah di Lapangan Bekasap, Riau. Kemudian yang terakhir adalah untuk menentukan perubahan muka air tanah dari bulan April ke bulan Oktober 2013 di Lapangan Bekasap, Riau.

\section{DATA DAN METODE}

Data pengukuran berasal dari pengukuran Vertical Electrical Sounding pada 30 titik di Lapangan Bekasap, Riau (Gambar 1). Pengukuran dilakukan dengan menggunakan konfigurasi Wenner.

Least squares atau yang disebut juga kuadrat terkecil merupakan metode pencarian model optimum dimana kesalahan kuadrat yang diperoleh bernilai minimum. Kerkurangan kecil pada data dapat mengakibatkan perubahan besar pada model. Untuk mengurangi masalah ini, dilakukan damping pada solusi inversi Ekinci dan Demirci (2008). Sehingga didapatkan solusi baru yang disebut sebagai damped least-squares Levenberg (1944); Marquardt (1963).

Singular Value Decomposition (SVD) adalah metode yang digunakan untuk menyelesaikan permasalahan geofisika dengan pemfaktoran matriks. Metode SVD terkenal pada analisis data geofisika karena baik secara matematis dan stabil secara numerik Maju (1994). Sebuah matriks $A n \times n$ atau $n \times p$ dapat difaktorkan menjadi sebuah produk dari tiga buah matriks lain.

Pengujian dilakukan dengan menggunakan tiga buah model sintetik. Setiap model terdiri dari lima lapisan. Pada model ini dilakukan forward modeling pada software RES1D untuk mendapatkan data sintetik. Model pertama (Gambar 2) memiliki lima lapisan, dimana lapisan pertama, ketiga, dan kelima memiliki nilai tahanan jenis semu lebih tinggi dinding dengan lapisan kedua dan keempat. Model kedua (Gambar 3) memiliki nilai tahanan je- nis semu lebih tinggi dari lapisan pertama, ketiga, dan kelima. Model ketiga (Gambar 4) memiliki nilai tahanan jenis semu yang semakin menurun.

Setelah dilakukan forward modeling, didapatkan nilai tahanan jenis semu sin- tetis. Kemudian untuk mendapatkan

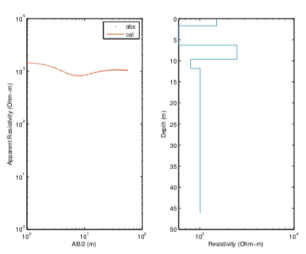

(a)

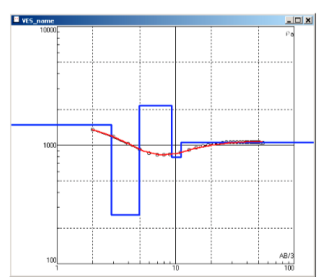

Gambar 2. Model Sintetik 1 (a). Pemodelan $D L S$ (b). Pemodelan IPI2Win.
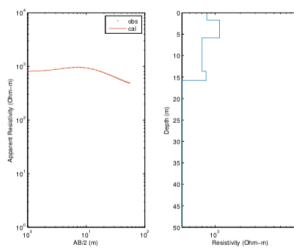

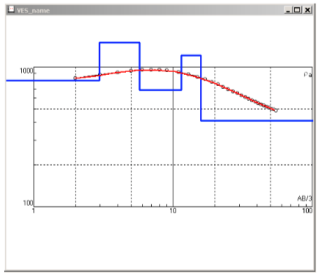

(b)
Gambar 3. Model Sintetik 1 (a). Pemodelan $D L S$ (b). Pemodelan IPI2Win.
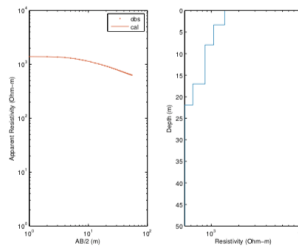

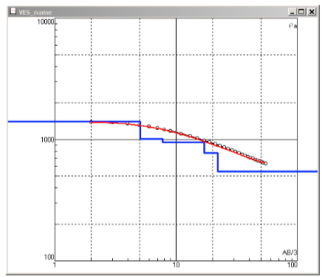

Gambar 4. Model Sintetik 1 (a). Pemodelan DLS (b). Pemodelan IPI2Win.

nilai tahanan jenis kalkulasi dan model kedalaman dilakukan inversi damped least-squares.

Proses pemodelan inversi yang digunakan untuk mendapatkan solusi atau model yang optimum. Pada tahap awal didapatkan data observasi $d^{\text {obs }}$ hasil pengukuran di lapangan dan model awal $m_{0}$. Pada model awal $m_{0}$ dilakukan forward modeling, sehingga dihasilkan data perhitungan $d^{\text {cal }}$. Kemudian data observasi dan data perhitungan dibandingkan. Apabila data belum fit, dilakukan proses modifikasi paramater model menggunakan solusi damped least-squares dengan penerapan Singular Value Decomposition pada matriks Jacobi. Proses ini dilakukan berulang atau iterasi hingga diperoleh konvergensi menuju solusi atau model optimum $m$ Grandis (2009).

\section{HASIL DAN PEMBAHASAN}

Pada titik G01, data hasil pengukuran dimodelkan menjadi empat buah lapisan. Lapisan kedua dan keempat memiliki tahanan jenis lebih rendah dibandingkan dengan lapisan 

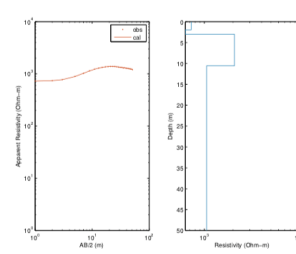

(a)

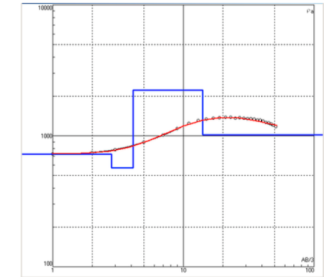

(b)
Gambar 5. Titik G01 (a). Pemodelan MATLAB (b). Pemodelan IPI2Win.
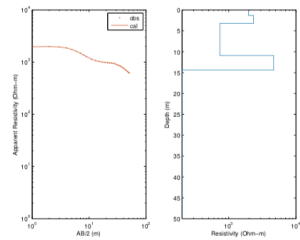

(a)

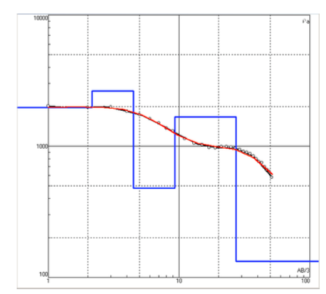

(b)
Gambar 6. Titik G07 (a). Pemodelan MATLAB (b). Pemodelan IPI2Win.
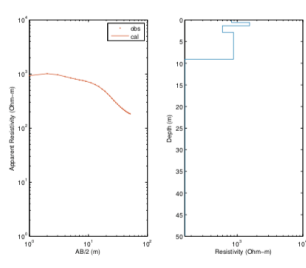

(a)

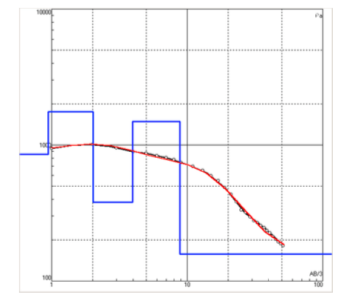

(b)
Gambar 7. Titik G10 (a). Pemodelan MATLAB (b). Pemodelan IPI2Win.

pertama dan ketiga (Gambar 5). Selanjutnya pada titik G07, data hasil pengukuran dimodelkan menjadi lima buah lapisan (Gambar 6). Lapisan ketiga dan kelima memiliki tahanan jenis yang jauh lebih rendah dari tahanan jenis lapisan lainnya. Sedangkan pada titik G10, data hasil pengukuran dimodelkan menjadi lima buah lapisan (Gambar 7). Lapisan pertama, ketiga, dan kelima memiliki tahanan jenis lebih rendah dibandingkan dengan tahanan jenis lapisan kedua dan keempat.

Pengukuran Vertical Electrical Sounding pada penelitian ini bertujuan untuk menentukan kedalaman muka air tanah. Kedalaman air tanah didapatkan dari hasil pemodelan inversi berupa model kedalaman. Pada model kedalaman, lapisan aquifer memiliki nilai tahanan jenis relatif lebih rendah dibanding lapisan di atasnya. Hal ini dikarenakan lapisan aquifer tersaturasi oleh air tanah.

Dari pengukuran pada dua waktu yang berbeda yaitu Bulan April dan Oktober 2013, juga didapatkan perubahan

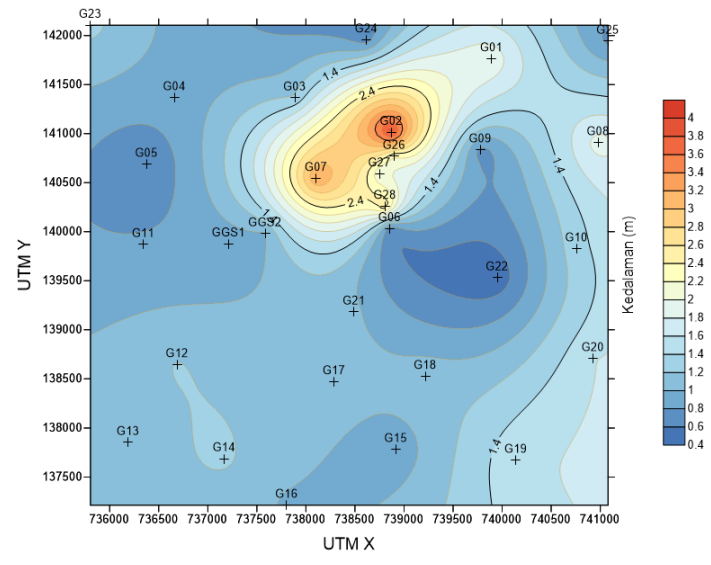

Gambar 8. Peta kedalaman muka air tanah April 2013.

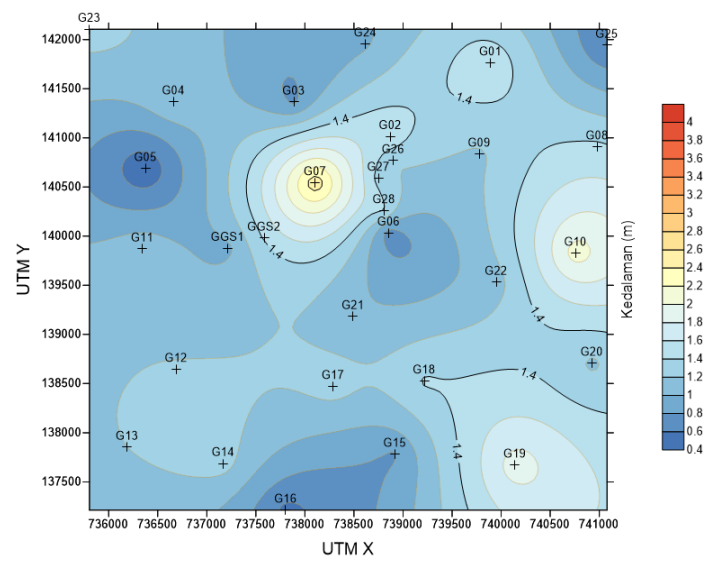

Gambar 9. Peta kedalaman muka air tanah Oktober 2013.

muka air tanah antara selang waktu kedua pengukuran. Dari model kedalaman yang diperoleh dari pemodelan inversi, secara umum hanya diinterpretasikan lapisan aquifer dan lapisan atas penutup aquifer, karena dari dua lapisan tersebut sudah dapat ditentukan muka air tanah. Lapisan pertama, yaitu lapisan penutup diinterpretasikan sebagai topsoil dengan nilai tahanan jenis $594-1700 \Omega \mathrm{m}$ dan pada beberapa titik sebagai batuan sedimen dengan nilai tahanan jenis 1700-13077 $\Omega \mathrm{m}$. Lapisan kedua merupakan unconfined aquifer yang diinterpretasikan sebgai batupasir, dengan nilai tahanan jenis $91-2188 \Omega \mathrm{m}$.

Nilai tahanan jenis lapisan dari pengukuran dipengaruhi oleh beberapa faktor. Salah satu faktor tersebut adalah porositas material pada suatu lapisan, dimana semakin besar nilai porositas dan semakin besar rongga yang terisi air maka nilai tahanan jenis akan semakin kecil. Kedalaman muka air tanah pada pengukuran bulan April berkisar sebesar 0.5- $4 \mathrm{~m}$ dengan kedalaman rata-rata $1.4 \mathrm{~m}$. Kedalaman muka air tanah pada pengukuran bulan Oktober berkisar sebesar 0.4-2.6 m dengan kedalaman rata-rata $1.2 \mathrm{~m}$. Pada beberapa titik pengukuran, kedalaman muka air tanah naik sebesar rata-rata $0.7 \mathrm{~m}$. Pada beberapa titik, kedalaman muka air tanah turun sebesar rata-rata $0.3 \mathrm{~m}$. 


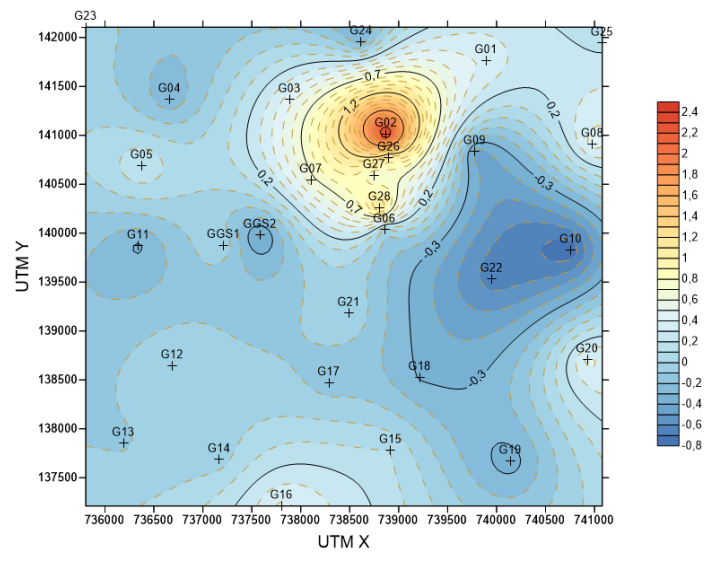

Gambar 10. Peta perubahan kedalaman muka air tanah dari bulan April hingga bulan Oktober 2013.

\section{KESIMPULAN}

Metode inversi damped least-squares dapat diaplikasikan untuk menentukan muka air tanah. Hasil pemodelan menghasilkan rms error rata-rata pada pengukuran bulan April sebesar $6.7 \%$ dengan rentang (0.8-13.6)\% dan Oktober sebesar $7.2 \%$ dengan rentang (0.9-15.5)\%. Besar rms error ratarata pada bulan April dan Oktober adalah 7\% dengan rentang (0.8-15.5)\%. Kedalaman rata-rata muka air tanah di Bekasap pada Bulan April adalah 1.4 meter dengan rentang kedalaman 0.5-4 m dan pada Bulan Oktober adalah 1.2 meter dengan rentang kedalaman 0.4-1.2 m. Kedalaman muka air tanah di Bekasap rata-rata mengalami kenaikan dari Bulan April hingga Bulan Oktober sebesar $0.2 \mathrm{~m}$

\section{DAFTAR PUSTAKA}

Dobrin, M.B. dan Savit, C.H. (1988). Introduction to Geophysical Prospecting. McGraw- Hill.

Kirsch, R. (2009). Groundwater Geophysics: A Tool for Hydrogeology. Springer.

Koefoed, O. (1979). Geophysical Principal. Elsevier Scientific Publishing Company.

Ghosh, D. P. (1970). The Application of Linear Filter Theory to the Direct Inter- pretation of Geoelectrical Resistivity Measurements. Doctoral thesis. TU Delft.

Ghosh, D. P. (1971). The Application of Linear Filter Theory to The Direct In- terpretation of Geoelectrical Resistivity Sounding Measurements. Geophys. Prospect.

Ekinci, Y. L. dan Demirci. A. (2008). A Damped LeastSquares Inversion Program for the Interpretation of Schlumberger Sounding Curves. Journal of Applied Sciences.

Levenberg, K. (1944). A Method for The Solution of Certain Non-Linear Problems in Least-Squares. Quart. Appl. Math

Marquardt, D. W. (1963). An Algorithm for Least-Squares Estimation of Nonlinear Parameters. Journal of the Society for Industrial and Applied Mathematics.

Meju, M. A. (1994). Geophysical Data Analysis: Understanding Inverse Problem Theory and Practice. Society of Exploration Geophysic Course Notes Series, No. 6, 1st Edition. SEG Publisher, Tulsa, Oklahoma.

Grandis, H. (2009). Pengantar Pemodelan Inversi Geofisika. Himpunan Ahli Geofisika Indonesia. 